\title{
REFLECTIONS ON VICTOR GORSHKOV \& ANASTASIYA MAKARIEVA WORK "KEY ECOLOGICAL PARAMETERS OF IMMOTILE VERSUS LOCOMOTIVE LIFE"
}

\author{
V. B. Keshelava', T. V. Keshelava² \\ ${ }^{1}$ Prostagnost LTD Infinitum (for Prostagnost), 316 Shabolovskaya street, Moscow, 115162, Russia \\ E-mail:varlam@taedison.ru \\ ${ }^{2}$ Astro Space Center of Lebedev Physical Institute of Russian Academy of Sciences, 84/32 Profsojuznaja street, Moscow, 117997, Russia \\ E-mail: tim.keshelava@gmail.com
}

Abstract. The modern biology widely uses methods of exact Sciences and, in particular, physics. However, physics and biology study objects with very different levels of integration of matter. This difference determines the fundamental differences in the nature of the studied objects and methods of obtaining knowledge. The indelicate application of methods previously used to describe inanimate nature, in fact, led to a split in the scientific community that studies life, to a lack of understanding and, often, even rejection of the results obtained by colleagues. As a result, mathematical modeling and theoretical generalizations of biological phenomena have not been properly developed. Currently, theoretical biology made a comeback, but for now it has to disguise itself as bioinformatics, transcriptomics, proteomics, metabolomics, systems biology, and so on. This note examines the historical background of the current situation and highlights its main, in our opinion, causes on the example of specific work related to ecosystem modeling.

Keywords: biological processes modeling, problems of mathematical modeling in biology, the interaction of physics and biology.

For citation: Keshelava V.B., Keshelava T.V. Reflections on Victor Gorshkov \& Anastasiya Makarieva work "Key ecological parameters of immotile versus locomotive life". Russian Journal of Ecosystem Ecology. 2020;5(2). Available from: https://doi.org/10.21685/2500-0578-2020-2-3

УДК 001.6, 001.8, 51-7, 57.01

\section{ОТЗЫВ НА СТАТЬЮ В. Г. ГОРШКОВА, А. М. МАКАРЬЕВОЙ «ФУНААМЕНТАЛЬНЫЕ ЭКОЛОГИЧЕСКИЕ ПАРАМЕТРЫ НЕПОДВИЖНОЙ И ПЕРЕАВИГАЮЩЕЙСЯ ЖИЗНИ»}

\author{
В. Б. Кешелава', Т. В. Кешелава ${ }^{2}$ \\ 'ООО «Простагност», Россия, 115162, г. Москва, ул. Шаболовка, 316 \\ E-mail:varlam@taedison.ru \\ ${ }^{2}$ Астрокосмический центр Физического института им. П. Н. Лебедева РАН, Россия, 117997, г. Москва, ул. Профсоюзная, 84/32 \\ E-mail: tim.keshelava@gmail.com
}

Аннотация. Современная биология широко использует методы точных наук и, в частности, физики. Однако физика и биология изучают объекты с очень разными уровнями интеграции материи. Это различие определяет принципиальные различия в природе изучаемых объектов и методах получения знаний. Неделикатное применение методов, ранее использовавшихся для описания неживой природы, фактически привело к расколу в научном сообществе, изучающем жизнь, к непониманию и, зачастую, даже неприятию результатов, полученных коллегами. В результате математическое моделирование и теоретические обобщения биологических явлений не получили должного развития. В настоящее время теоретическая биология возвращается, но пока ей приходится маскироваться под биоинформатику, транскриптомику, протеомику, метаболомику, системную биологию и так далее. В настоящей заметке рассматриваются исторические предпосылки сложившейся ситуации и выделяются ее основные, на наш взгляд, причины на примере конкретной работы, посвященной моделированию экосистем.

Ключевые слова: моделирование биологических процессов, проблемы математического моделирования в биологии, взаимодействие физики и биологии. 
Discussing the problems of mathematical modeling in biology, one should always keep in mind the complicated history of the subject. A historical perspective would give a better understanding of the context of the problems discussed, and their significant complexity.

The history of the field began in 1944, when Erwin Schrödinger published his book "What is Life? The Physical Aspect of the Living Cell" [5]. A brilliant theoretician, Schrödinger tried to consider biological phenomena from a physical perspective, analyzing them in a traditional, for a physical mind, way. The renown physicist did not give the final answer to the question he posed in the title of his book - yet in all respects, the book turned out to be profound and interesting. In the book, Schrödinger made several predictions (which later came true) and hypothesized that biology might have its own laws (like the laws of physics), which had yet to be discovered.

By the time Schrödinger's work came out, the field of theoretical physics had been in a kind of crisis. There was an impression that physical science had come to an end: that all fundamental laws had been discovered, and physicists would soon become jobless. As a result, many physicists inspired by Schrödinger's vision rushed into biology. This "advent of physicists" revealed, for the first time, several problems related to the cooperation between physics and biology. Among those problems, which have been complicating the application of physical and mathematical methods to the analysis of biological systems for a long time, we would like to highlight two: a fundamental problem and a psychological one.

\section{The fundamental problem of cooperation between physics and biology}

Physics and biology consider matter at essentially different levels of its integration, thus determining fundamental differences in the character of the studied objects and the ways of obtaining knowledge. In a few words, the fundamental differences can be described as simple versus complex and easy versus difficult. Physics considers simple systems, yet obtaining new physical knowledge is difficult: it requires deep immersion in the details of the phenomenon under study. Biology, on the other hand, deals with very complex systems, yet it is usually easy to discover something new, because biological systems are characterized by variable behavior and diverse reactions to the external stimuli. This does not mean, however, that biologists cannot or should not strive for a thorough understanding of the important factors that affect biological processes - in all their totality.
To give a specific example, physics has achieved a great success in describing high-energy interactions of simple objects (elementary particles, atoms of monatomic gases - i.e., systems with a small number of internal-state parameters). In models, these objects can be further simplified: described as having an ideal shape, being absolutely elastic, indestructible and so on. Moreover, physicists usually consider systems in which only a minority of factors are determinative, and many interactions between objects can be neglected. Thus, physical modeling assumes that all objects of a selected class respond equally to external influences and also affect each other uniformly.

At a higher level of organization (and lower interaction energies), the beloved ball-shaped objects of physicists and mathematicians begin to form molecules. Which means that the objects of modelling change cardinally. The dynamics of molecular objects is determined by a whole bunch of interactions, and none of them can be neglected. As a result, the behavior of molecular objects becomes much more diverse. At this point, the methods of physics used to describe the systems are smoothly replaced by the more relevant methods of chemistry.

Clearly, chemical phenomena do not violate the laws of physics. Yet even abiding by these laws, chemical phenomena still have their own complexity, which cannot be reduced to the characteristics of the physical components of a chemical system. That is why approaches operating with the system level properties of chemical objects (such as "valency" and "redox potential" of atoms and molecules) turn out to be more appropriate for the description of chemical nature. These properties are treated as basic characteristics of chemical objects, which is nontrivial from the physical viewpoint.

As the complexity of the systems, whose behavior is defined within the framework of chemistry, levels up, patterns of organic chemistry, biochemistry, and molecular biology emerge. Going further, information exchange, metabolic patterns, cell physiology, physiology of unicellular and multicellular organisms (among which archaea, bacteria, actinomycetes, fungi, yeasts, protists, plants, insects, chordates and others differ in many essential parameters) appear - and only after, at the upper steps of this complexity ladder, trophic chains, ecosystems and other high-level systems come into play.

The transitions between the levels of matter organization ${ }^{1}$ are characterized by a number of specific features, some of which are counterintuitive.

${ }^{1}$ Even at first glance, there are more than 10 of them, starting from the transition of inanimate to animate nature. 
There is no doubt that each of the transitions is unique and should be analyzed separately. In many cases, however, a transition can be described as formation of a super-object from the combination of entities of the previous level: elementary particles form atoms; atoms form substances and small molecules; small molecules form polymers; small molecules and polymers form biological cells etc. If you consider a hierarchy of objects of different levels of complexity, then in the terminology proposed by Karl Ludwig von Bertalanffy [1], objects of each of the lower level of hierarchy would interact with each other and form an integral whole in the form of a complex object, which Bertalanffy called a "system".

Additional complexity of a system in Bertalanffy's terms comes from level mixing: from the fact that the system is formed from objects of different levels of hierarchy. For example, components of a biological cell are:

- atoms/chemical elements (ions of hydrogen, sodium, and potassium, atoms of iron, cobalt, etc.);

- small inorganic and organic molecules (ammonium, nitrite, nitrate, phosphate, carbon dioxide, methane, ethane, ethanol, pyruvate, organic acids, etc.);

- small biological molecules (sugars, ethanolamine, amino acids, polyamines, nucleotides, etc.);

- biological molecules of average molecular weight (ATP, NAD, FAD, Ac-CoA, etc.);

- lipids and fats;

- polymers (DNA, RNA, proteins);

- polymers of variable composition and amorphic structure (lignin, cellulose, peptidoglycans, glycopeptides, starch, etc.).

Many attempts have been made to formulate a model of a biological organism. The problem, however, has not been solved yet, which is not surprising given a multicomponent nature of the organism and a multilevel nature of its components. Nevertheless, researchers have amassed a lot of important data on the mechanisms of formation of the individual properties of biological objects. Keystone achievements in this field were reported at the $1^{\text {st }}$ Waddington symposium [6]. There have been other symposia as well, yet the model seems to be far from completion - even today.

The modeling of environmental processes is the most difficult task, because climate, weather etc. further increase the complexity of the system. Dealing with environmental processes, one should also take into account their unpredictability. Unpredictability of chaotic systems was discovered by Lorentz upon simulation of weather phenomena [4].

\section{Methodological problems of modeling complex objects}

The value of a mathematical model is determined by two aspects. First, the model provides specific information about behavior of the simulated system under specific conditions. Second, the model can be used as a substitute for the simulated system in theoretical studies. The latter allows one to obtain new knowledge about the simulated system by studying its mathematical model.

The methodology that is, in a sense, opposite to mathematical modeling, is the methodology characteristic of the humanities and philosophy: a verbal description of the subject. The description is often given in general terms, and the more general they are, the more adequate is the description. The same goes true for mathematical modeling: a general model would be more accurate in terms of its correspondence to the simulated system. However, an overly generalized approach would limit the intensional value of the model.

It should be stressed that the utility of a model is directly proportional to the degree of its approximation to the simulated system. Thus, the usual way of gaining knowledge is the transition from understanding formulated in a verbal form through conceptualization - to the mathematical model.

The essential and "rocky" part of this path is conceptualization. This stage is dedicated to building a strict conceptual framework. This is the only way to uniquely algorithmize the main properties of the modeled entity as a set of linguistic statements. Mathematical modelling is only possible after a conceptual model is created. At the same time, the value of a model is not diminished if it is incomplete (not all factors are taken into account) and has some limitations (imposed by the set of conditions under which the model is examined) given that everything is stated explicitly.

In reality, the specialists who are well-versed in the modeled phenomena and those who are experts in the methods of mathematical modeling often have dramatically different backgrounds. Which means that in the process of model construction, a crucial step is transition of knowledge from the subject specialist to the modeler. This problem was discussed in the 1980s in the context of expert systems building. Formalization of human knowledge turned out to be a not-trivial task and, eventually, knowledge engineering emerged as a separate research field $[2,3]$.

As marked, wholistic properties of a system cannot be reduced to the properties of its components. Even more, they cannot be described in the terms used at the level of components. Correspond- 
ingly, one cannot study wholistic properties of a system if the system is only partially described by the model (or if only a part of the system is simulated). Thus, the reduction of object properties into an adequate model of the object should be done very carefully. A clear understanding of what was omitted and abstracted from in the process of model construction is highly desirable.

\section{A problem of cooperation between physicists and biologists}

The second problem, complicating the application of mathematical models in biology, is psychological. This problem is rooted in the fact that physicists who moved into biology did not necessarily follow Bertalanffy's path - the path that went along the concepts of emergence, system transition, synergetics, dissipative structures etc. and led to the development of theory of complex systems.

Those who did not pursue the path of von Bertalanffy, went in the direction which had led them to the field that nowadays is known as biophysics. Among the achievements made by researchers on this path is a great number of instrumental methods developed - including methods which paved the way for molecular biology.

However, the reputation of physicists who came into biology was compromised by a bunch of individuals with superiority complex: "What? Biology? Ah, right. We know: pistils and stamens. Haha". Such an attitude made them confident that there was no particular need to dive into the specifics of "pistils and stamens". They seemed to think that their shallow knowledge of biology was enough to successfully model biological processes. "Don't worry! Now that we are here, with our precise physical methods and strict mathematical analysis, we can finally shed light onto your obscure discipline" - and they called their field "theoretical biology".

In the long run, this particular brand of biological modelling, known as "theoretical biology", had become completely discredited in the eyes of biological community. In the last two decades of the $20^{\text {th }}$ century, "theoretical biology" had been a polite form of sneer, equivalent to "baseless pseudoscientific speculations generously spiced with mathematical equations".

This situation also had a negative impact on the biological science itself. With such an example before their eyes, a few generations of biologists made sure to avoid thorough mathematical and synthetic analysis altogether. As a result, biological reductionism often leads to the triumph of empiricism. Therefore, biological science produces an avalanche of disparate empirical information that is often useless on closer inspection.

The situation began to change after the development of nucleic acid and protein sequencing technologies. These technologies provided a colossal stream of information, which was simply impossible to process in a traditional way. Theoretical biology made a comeback - yet has to disguise itself as bioinformatics, transcriptomics, proteomics, metabolomics, system biology etc.

\section{Back to specifics}

The submitted paper focuses on mathematical modelling of the biosphere as a whole. It is clear that, in view of the aforesaid, we should be especially careful and meticulous when it comes to this kind of research. Alas, the authors did not follow the guidelines of knowledge engineering and made some common mistakes.

Modeling a complex system, one should, first of all, comply with the methodology of conceptualization of the linguistic form of knowledge, as well as methodology of verification of the conceptual model. In our mind, this preparatory work was not thorough enough. Many statements, which ought to be substantiated, are introduced by the authors as self-evident.

If the methodology of reasoning and conceptual representation of the system is flawed, the whole work becomes meaningless. In this case, even if the results seem to be correct, the conclusions drawn from them can be a consequence of both chance and unintentional/intuitive choice made by the authors in favor of a certain concept.

In our opinion, the paper illustrates the problematic situation which arises when specialists in mathematical modeling take the initiative too early.

Here is a list of just some statements which, from our point of view, are problematic.

1. The authors consider the thin layer of life as having "absolute stability" - as if stability is the purpose of life per se. This statement is the basis of the authors' logic. The statement seems dubious, though - not to mention the absence of any justification.

2. Respiration is indicated as the only mechanism for organic matter decomposition. But among microorganisms, anaerobic processes are much more common. By the way, the gastrointestinal tract of animals is also characterized by anaerobic metabolism;

3. The authors ignore the spectral inefficiency of photosynthesis: plants do not use all the solar energy, even the energy in the visible range of the spectrum.

4. Formula 3 is erroneous.

5. The "coincidence" of the rates of biomass production and decomposition is presented as a spe- 
cial feature of life. This view is in contradiction with the deposition of significant amounts of organic matter (in the form of coal and oil, for example).

6. The authors consider carbon dissolved in the ocean as passive and virtually excluded from the biogeochemical cycle.

7. On the basis of a rather strange statement that "Large animals ... consume live plant biomass ... introducing disturbances into the fluxes of organic matter synthesis" follows an absurd thesis about the possibility of unconstrained growth of the herbivore population, which theoretically can only take place in the absence of predators, parasites and diseases. The latter would indicate, however, that the ecosystem is, at the very least, unhealthy. Simulating such an ecosystem may be of some interest, but it has nothing to do with the modeling of the entire biosphere.

8. There is no sufficient reason behind the statement about the evolutionary meaning of social behavior of animals as a way to combat mutations. This oversimplification may be partially true for monogamous animals, but monogamy is rare in the animal world.
9. The statement about inability of plants to accumulate photons does not have any sense, since the energy of photons is transformed into the energy of chemical compounds, which can be and are accumulated by plants. In fact, the growth of tree biomass is the accumulation of photon energy.

\section{Conclusion}

In General the reviewed article seems to us an interesting attempt to model the entire biosphere. At the same time, a number of specific assertions, on which the model is based, are dubious and insufficiently grounded. On the whole, the work does not seem to be up to the standards of a scientific publication, the purpose of which is to report new and clearly formulated results.

The major criticism of the paper is not about specific inaccuracies (they can be corrected). It is about general methodological errors, which specialists working in the field have known for decades.

\section{Библиографический список}

1. Bertalanffy von, L. General System Theory - A Critical Review / L. von Bertalanffy // General Systems. - 1962. Vol. VII. - P. 1-20.

2. Cooke, N. M. A Formal Methodology for Acquiring and Representing Expert Knowledge / N. M. Cooke, J. E. McDonald // Proc. IEEE. - 1986. - Vol. 74, № 10. - P. 1422-1430.

3. Building Expert Systems / ed. by F. Hayes-Roth, D. A. Waterman, D. B. Lenat. - Massachusetts, USA : AddisonWesley Publishing Company, 1983.

4. Lorenz, E. N. Deterministic nonperiodic flow / E. N. Lorenz // Journal of the Atmospheric Sciences. - 1963. Vol. 20. - P. 130-141.

5. Schrödinger, E. What is life? The physical aspect of the living cell / E. Schrödinger. - Cambridge University Press, 1944.

6. Towards a theoretical biology. I. Prolegomena / ed. by C. H. Waddington // An IUBS Symposium. - Birmingham : Aldine Publ. Comp., 1968.

\section{References}

1. Bertalanffy von L. General Systems. 1962, vol. VII, pp. 1-20.

2. Cooke N. M., McDonald J. E. Proc. IEEE. 1986, vol. 74, no. 10, pp. 1422-1430.

3. Building Expert Systems. Ed. by F. Hayes-Roth, D. A. Waterman, D. B. Lenat. Massachusetts, USA: Addison-Wesley Publishing Company, 1983.

4. Lorenz E. N. Journal of the Atmospheric Sciences. 1963, vol. 20, pp. 130-141.

5. Schrödinger E. What is life? The physical aspect of the living cell. Cambridge University Press, 1944.

6. Towards a theoretical biology. I. Prolegomena. Ed. by C. H. Waddington. An IUBS Symposium. Birmingham: Aldine Publ. Comp., 1968. 